\title{
Mario Losano no Brasil: entre política, sociologia e história do direito (2012-2018)
}

\author{
Mario Losano in Brazil:between politics, sociology and the history \\ of law (2012-2018)
}

Gustavo Silveira Siqueiral

\begin{abstract}
RESUMO:
Mario Losano é um dos mais importantes pensadores contemporâneos do Direito. Suas obras tem relação com a história do direito, a teoria do direito e a sociologia jurídica. Em comemoração aos 80 anos de nascimento de Mario Losano, o presente ensaio pretende descrever as relações e publicações do autor com o Brasil entre 2012 e 2018.
\end{abstract}

\section{PALAVRAS-CHAVE:}

Mario Losano; História do Direito.

\begin{abstract}
:
Mario Losano is one of the most important contemporary thinkers of law. His works are related to the history of law, the theory of law and legal sociology. In celebration of the 80th birthday of Mario Losano, this essay aims to describe the author's relations and publications with Brazil between 2012 and 2018.
\end{abstract}

\section{KEYWORDS:}

Mario Losano; Law Story.

As relações de pesquisa do professor Mario Losano no Brasil começaram nos anos 70 com seus primeiros trabalhos de Informática Jurídica. Desde então foram diversos os temas, os debates e as pesquisas que Mario Losano elaborou e publicou sobre e no Brasil. O presente capítulo pretende resgatar a trajetória de Losano nos últimos seis anos no Brasil, tendo como foco especial os cursos e as pesquisas que participou na Universidade do Estado do Rio de Janeiro. Além disso, é também um texto com toque pessoal, pois relaciona as pesquisas do autor do capítulo com as pesquisas do autor objeto de pesquisa.

\footnotetext{
${ }^{1}$ Professor Associado e Coordenador de Pós-Graduação em Direito da UERJ. Bolsista de Produtividade do CNPQ, Pesquisador do Estado do Rio de Janeiro (FAPERJ-JCE) e Secretário do Instituto de História do Direito (IBHD). É Professor da Universidade Estácio de Sá, tem estágio pós-doutorado no Max-Planck-Institut fur europaische Rechtsgeschichte (Frankfurt) e atua como Professor Visitante do Mestrado da Universidade Autônoma de Lisboa.
} 
Li os primeiros livros do professor Mario Losano na graduação em Direito. Sempre fui um admirador da grandeza e da complexidade da sua obra, e o livro "Os grandes sistemas Jurídicos"2 sempre foi uma inspiração para as minhas pesquisas. Nos últimos seis anos a participação do professor Mario Losano intensificou-se e tornou-se singular. Suas participações em eventos no Brasil tornaram-se extremante intensas e produziram diversos frutos.

Em 2012 fui convidado pelo Max-Planck-Institut für Europäische Rechtsgeschichte (Frankfurt - Alemanha) para um o evento "Modernización y derecho privado en América Latina y Europa en la primera mitad del siglo XX" que aconteceu em Buenos Aires, Argentina, no Instituto de Investigaciones de Historia del Derecho, em julho de 2012. Pesquisadores de diversos países estavam presentes e pude apresentar minha pesquisa sobre História do Direito e movimentos sociais nas greves brasileiras do início do século $\mathrm{XX}^{3}$, bem como ouvir a pesquisa do professor Mario Losano sobre a troca de cartas de Eduardo Couture e Pietro Calamandrei. ${ }^{4}$

Foram nos debates do evento, primorosamente organizado por Thomas Duve, María Rosario Polotto e Thorsten Keiser, que o professor Losano mencionou que também estava pesquisando a relação entre direito e movimentos sociais. A afinidade política, teórica e temática foi imediata. Conversamos muito e definimos novos projetos que aconteceriam nos anos seguintes. De certa forma, este artigo explica os projetos, pesquisas e debates decorrentes do encontro entre um brasileiro e um italiano, que começaram a conversar discutindo a vida de um austríaco (Hans Kelsen), na Argentina, em um evento organizado por um importante instituto de pesquisa alemão.

Losano, que fala português e outras línguas fluentemente, aceitou vir ao Brasil novamente e iniciar laços de pesquisa com o Rio de Janeiro, cidade em que tinha poucos contatos e que hoje é a sua principal referência de pesquisa no Brasil.

\footnotetext{
${ }^{2}$ Mario G. LOSANO, Os grandes sistemas jurídicos, São Paulo, Martins Fontes, 2007.

${ }^{3}$ Gustavo S. SIQUEIRA, Republic and Strike Action in the Beginning of the 20th Century: A Debate between the 1906 Strike and Legal History, in María Rosario POLOTTO, Thorsten KEISER, Thomas DUVE (eds.), Derecho privado y modernización: América Latina y Europa en la primera mitad del siglo XX Global Perspectives on Legal History, Frankfurt am Main, Max Planck Institute for European Legal History, 2015, v. 1, p. 199-211, Open Access Publication, http://dx.doi.org/10.12946/gplh2.

${ }^{4}$ Mario G. LOSANO, Tra Uruguay e Italia: Couture e Calamadrei, due giuristi democratici nell'epoca delle dittature europee, in María Rosario POLOTTO, Thorsten KEISER, Thomas DUVE (eds.), Derecho privado y modernización: América Latina y Europa en la primera mitad del siglo XX Global Perspectives on Legal History, Frankfurt am Main, Max Planck Institute for European Legal History, 2015, p. 275-312, Open Access Publication, http://dx.doi.org/10.12946/gplh2.
} 
Inspirado pelas polêmicas do movimento de Beppe Grillo, na Itália, pelos "Indignados", na Espanha, e pelos "Piraten", na Alemanha, Mario Losano ministrou o seu primeiro curso na Faculdade de Direito da UERJ entre 7 e 12 de novembro de 2013. O curso "Movimentos e política na Europa contemporânea" informava aos brasileiros os movimentos políticos e sociais que estavam florescendo no continente europeu naquele momento. Losano se mostrava ao público brasileiro como um pesquisador atento aos temas atuais e em constante atualização. O curso foi disponibilizado online e hoje pode ser acessado pela internet no site http://www.ppgduerj.com/videos.html.

Foi neste momento que pude debater com Losano a minha tese de doutorado intitulada "História do Direito pelos movimentos sociais"; comparamos em aulas e em artigos publicados posteriormente as visões sobre movimentos sociais na Europa e no Brasil e suas relações com o direito.

No mesmo mês, em 14 de novembro de 2013, Mario Losano recebeu da Universidade Federal de Pernambuco (UFPE) o título de Doutor Honoris Causa e proferiu a aula magna "Privacidade versus segurança na época do terrorismo". Mais uma vez, Losano debatia temas atuais da Europa e lançava seu pensamento crítico sobre os recentes acontecimentos.

Na Universidade Federal do Paraná (UFPR), poucos dias após o título concedido pelo UFPE, Losano ministrou mais duas palestras, retornando a sua tradição de grande pensador da teoria e da filosofia do Direito. No dia 18 de novembro expôs sobre a história do pensamento sistemático no direito, e no dia 19 do do mesmo mês, apresentou um trabalho sobre Hans Kelsen e o sistema jurídico.

Com um fôlego e uma vitalidade que surpreendeu os pesquisadores brasileiros, Mario Losano ainda aceitou o desafio de ministrar uma palestra na Universidade Estadual de Londrina (UEL), também no estado do Paraná, sobre o sistema do direito e Hans Kelsen. Ainda, proferiu outras duas palestras na Pontifícia Universidade Católica do Paraná (PUC-PR): uma sobre os movimentos sociais na Europa e outra sobre a relação entre a Carta del Lavoro italiana e a Consolidação das Leis do Trabalho (CLT) brasileira.

\footnotetext{
${ }^{5}$ Gustavo S. SIQUEIRA, História do Direito pelos movimentos sociais: cidadania, experiências e antropofagia juridica nas Estradas de Ferro (Brasil, 1906), Rio de Janeiro, Lumen Juris, 2014.
} 
A viagem de Mario Losano ao Brasil em 2013 atraiu pesquisadores de todo o país em suas palestras. Destes encontros surgiram novos convites e diversas instituições queriam conhecer de perto uma das mais importantes referências teóricas do direito no Brasil. Losano não negou o desafio. Ainda fez uma palestra na Universidade Federal de Santa Catarina (UFSC) sobre Rudolf von Jhering e sua relação com a dogmática e a sociologia jurídica, e, no dia 28 de novembro de 2013, encerrou suas atividades brasileiras do ano com uma palestra na Universidade Federal Fluminense (UFF) sobre Hans Kelsen e sua bibliografia cultural.

O ano de 2013 foi marcado na história das Faculdades de Direito do Brasil com a visita de Mario Losano ao país. De Norte a Sul, viajando milhares de quilômetros, a gentileza e a generosidade de Mario Losano contribuíram para que suas obras fossem ainda mais difundidas no país.

Em agosto de 2014 a Revista da Faculdade de Direito da Universidade Federal do Paraná (UFPR) publicou o artigo "O valor da Justiça na obra de Kelsen" discutiu o prisma epistemológico adotado por Kelsen quando analisa o valor da justiça na Teoria Pura do Direito e outras obras. Foi o primeiro artigo do autor em uma das mais importantes revistas jurídicas do Brasil. A revista inaugurava um ano que seria marcado por outras passagens de Mario Losano no Brasil.

Em 03 de outubro de 2014, de volta ao Brasil, Mario Losano proferiu a palestra de abertura do principal evento jurídico do país naquele ano: "Da teoria da norma à teoria do ordenamento: o positivismo jurídico entre Kelsen e Bobbio"7 . O evento, realizado na Faculdade de Direito da Universidade Federal do Rio de Janeiro, reuniu os principais pesquisadores de teoria do direito do Brasil e diversos convidados internacionais. Os debates do congresso internacional que reuniu pesquisadores da América do Sul e da Europa se tornaram livro em 2016 e a palestra de abertura "O positivismo na conformação do pensamento de Norberto Bobbio" transformou-se em um capítulo do livro.

\footnotetext{
${ }^{6}$ Mario G. LOSANO, O valor da justiça na obra de Kelsen, «Revista da Faculdade de Direito UFPR», 2014 , v. 59 , n. 2, p. 31-45.

${ }^{7}$ Cecília Caballero LOIS, Gustavo Silveira SIQUEIRA, Da teoria da norma à teoria do ordenamento: o positivismo jurídico entre Kelsen e Bobbio, Belo Horizonte, Arraes Editores, 2016.
} 
Já entre os dias 6 e 10 de outubro de 2014, atendendo a convite da CAPES Coordenação de Aperfeiçoamento de Pessoal de Nível Superior do Ministério da Educação da República Federativa do Brasil, o Professor Mario Losano ministrou a Escola de Altos Estudos com o curso "Reflexão Filosófica e militância democrática em Noberto Bobbio - dez anos depois da sua morte." A Escola de Altos Estudos é o mais importante convite do Ministério da Educação do Brasil para um professor ministrar um curso. O curso de Mario Losano foi contemplado com o convite do Ministério e foi realizado na Universidade do Estado do Rio de Janeiro (UERJ). Transmitido pelo canal de televisão da Universidade, o curso também foi transmitido ao vivo pela internet e diversos participantes de todo o país puderam assistir, além da possibilidade de formular perguntas ao vivo ao palestrante. O curso está disponível na internet http://www.ppgduerj.com/videos.html e um DVD com todo o curso foi distribuído para todos os programas de pós-graduação em direito no país.

Pesquisador interdisciplinar, Losano ainda expôs, no dia 8 de outubro de 2014, nos salões do tradicional Instituto Histórico Geográfico Brasileiro, uma palestra sobre um autor brasileiro Tobias Barreto, intitulada "Um olhar europeu sobre o germanista sergipano". Losano mostrava-se, mais uma vez, como um pesquisador flexível, multifacetado e mundial. Seus temas eram sempre completos e extremamente detalhados.

Completando a maratona jurídica, Losano viajou para São Paulo onde fez mais duas palestras na Faculdade de Direito da Universidade de São Paulo (USP). A primeira, no dia 13 de outubro, sobre a "Tradição da filosofia do direito em Turim e o jovem Norberto Bobbio"; e no dia 15 de outubro, sobre “A 'conversão' de Bobbio à teoria pura do direito.” Entre as duas palestras, no dia 14 de outubro, Losano falou sobre o pluralismo político e a democracia no pensamento de Norberto Bobbio na Escola Paulista da Magistratura.O entusiasmo e a animação de Mario Losano contagiava a todos. Depois de vários dias no país, o professor ainda teve fôlego de sobra para ministrar 3 conferências em 3 dias seguidos.Discípulo de Norberto Bobbio, Losano contribuiu ainda mais para a divulgação das obras do professor italiano no Brasil.

Encerrando seus eventos no Brasil, Losano viajou até o interior do país e, no campus de Três Lagoas, da Universidade Federal do Mato Grosso do Sul (UFMS), ministrou uma conferência sobre a informática e a sustentabilidade no futuro imediato. Aqui é interessante destacar que Losano voltou ao primeiro tema que desenvolveu no Brasil: a informática jurídica. 
Assim, é possível dizer que o ano foi também um reencontro do autor com o Brasil com praticamente todos os temas que trabalhou. Desta forma, o ano de 2014 foi uma síntese e uma reapresentação de Losano ao país, firmando mais solidamente a relação intelectual de suas obras com o país.

No ano de 2015 Losano não viajou ao Brasil, mas publicou no país dois importantes artigos. Em "Sociologia Jurídica e Histórica, história do direito e, no Brasil, "antropofagia jurídica" 8 , Mario Losano escreveu na Revista da Faculdade de Direito da UFPR um comentário e uma crítica a minha tese de doutorado intitulada "História do Direito pelos movimentos sociais", publicada em 2014, no Rio de Janeiro ${ }^{9}$ No texto, Losano discutiu a relação entre sociologia do direito e história do direito e problematizou a ideia de antropofagia jurídica que desenvolvi em minha tese. O objeto da antropofagia jurídica é a ideia do pesquisador não apenas “comer" e "conhecer" as teorias estrangeiras, mas também questioná-las e adaptá-las aos diferentes contextos e países. Nenhuma ideia é copiada com perfeição. Toda cópia é uma nova ideia que funciona em diferentes ambientes. As reações da cópia com o ambiente nunca é igual ao original. Sendo assim, o direito nunca é o mesmo, por mais que seja descrito como igual ou como cópia.

Ter o texto lido e debatido por um dos pesquisadores mais importantes do direito foi uma das maiores honras da minha carreira como pesquisador. No ano seguinte, publiquei na mesma revista da UFPR uma resposta a alguns questionamentos que Mario Losano fez ao meu trabalho. ${ }^{10}$

Em 2015, na Revista da UFPR, Mario Losano também publicou o artigo "Il positivismo nellévoluzione de pensiero di Norberto Bobbio", trabalho que, em parte, já tinha sido debatido no país. Aqui é importante perceber como as visitas de Losano ao Brasil também renderam publicações frutos de pesquisas apresentadas no país.

\footnotetext{
${ }^{8}$ Mario LOSANO, Sociologia Jurídica e Histórica, história do direito e, no Brasil, "antropofagia jurídica", «Revista Direito e Praxis», 2015, v. 6, n. 3. Texto publicado em italiano na Revista da Faculdade de Direito da Universidade Federal do Paraná: Mario LOSANO, Sociologia giuridica e storica e, in Brasile, "Antropofagia Giuridica", «Revista da Faculdade de Direito UFPR», 2015, v. 60, n. 2, p. 11-40.

9 Gustavo Silveira SIQUEIRA, História do Direito pelos movimentos sociais: cidadania, experiências e antropofagia juridica nas Estradas de Ferro (Brasil, 1906), Rio de Janeiro, Lumen Juris, 2014.

${ }^{10}$ Gustavo Silveira SIQUEIRA, Pequeno ensaio sobre antropofagia jurídica: por uma sociologia histórica do direito brasileiro?, «Revista da Faculdade de Direito UFPR», 2016, v. 61, n. 1, p. 303-312.
} 
O texto "O positivismo da conformação do pensamento de Norberto Bobbio" apresentado por Mario Losano, em 2014, no Congresso "Da Teoria da Norma à Teoria do Ordenamento", foi publicado com um livro homônimo em $2016 .{ }^{11}$

No mesmo ano, que seria marcado por outra viagem intensa ao Brasil, Losano voltou a debater comigo as relações de Hans Kelsen com o Brasil. Foi neste ano que Losano traduziu e fez uma introdução ao parecer de Hans Kelsen para a Assembleia Nacional Constituinte brasileira, em $1933^{12} \mathrm{O}$ texto, publicado em português, alemão, espanhol e italiano, possibilitou aos pesquisadores de todo o mundo o acesso a um importante texto de Hans Kelsen, pouco conhecido no mundo jurídico internacional. No mesmo ano, após algumas discussões com Losano, publiquei um artigosobre o contexto histórico do parecer no Brasil. ${ }^{13}$

Em agosto de 2016, Mario Losano voltou ao Brasil para outra série de palestras. Os debates atuais e os temas clássicos novamente se misturavam e demonstravam a capacidade do pesquisador de atualizar-se e discutir profundamente as bases do pensamento jurídico.

Na Faculdade de Direito da Universidade de São Paulo e na Universidade Mackenzie, respectivamente em 22 e 26 de agosto de 2016, Losano palestrou sobre o pluralismo jurídico na Europa e os problemas jurídicos da imigração muçulmana, tema que ocupava páginas de diversos jornais no Brasil por conta dos recentes acontecimentos europeus. No dia seguinte, na Pontifícia Universidade Católica de São Paulo, o tema foi a "importância e a atualidade o pensamento de Norberto Bobbio", assunto que falaria novamente no Instituto Norberto Bobbio de São Paulo, em 24 de agosto (Norberto Bobbio e a democracia na Itália: a tensão entre teoria e realidade), e novamente na Pontifícia Universidade Católica de São Paulo, em 25 de agosto (Norberto Bobbio e a democracia na Itália: a tensão entre teoria e realidade.)

Depois de diversas palestras em São Paulo, Losano ministrou um curso entre 27 de agosto e 06 de setembro na Universidade do Estado do Rio de Janeiro. O curso "Os grandes sistemas jurídicos e o Ocidente", que trouxe ao debate importantes trabalhos de Losano, foi

\footnotetext{
${ }^{11}$ Cecília Caballero LOIS, Gustavo Silveira SIQUEIRA, Da teoria da norma à teoria do ordenamento: o positivismo jurídico entre Kelsen e Bobbio, Belo Horizonte, Arraes Editores, 2016.

${ }^{12}$ Mario LOSANO, O parecer de Hans Kelsen de 1933 sobre a Assembleia Nacional Constituinte do Brasil Parecer em alemão, espanhol e italiano, «Revista Direito e Práxis», 2016, [S.1.], v. 7, n. 2, p. 624-648.

${ }^{13}$ Gustavo Silveira SIQUEIRA, O parecer de Kelsen sobre a Constituinte brasileira de 1933-1934 / The Kelsen`s work about Brazilian Constituent 1933-1934. «Revista Direito e Práxis», 2015, [S.1.], v. 6, n. 2, p. 348-374.
} 
transmitido pela TV UERJ,gravado e disponibilizado no canal do Programa de Pós-graduação em Direito da UERJ (www.ppgduerj.com).

Em 2018, Mario Losano voltou ao Brasil para outra intensa sessão de conferências. Em 26 de outubro palestrou sobre as tendências de direita na Europa atual e entre 29 e 31 de outubro ministrou outro curso sobre os grandes sistemas jurídicos, agora com foco nas convivências contemporâneas de sistemas jurídicos, na Faculdade de Direito da Universidade do Estado do Rio de Janeiro.

Assistindo todas as polêmicas que giravam em torno das eleições presidenciais brasileiras em 2018, Losano também palestrou na Universidade Federal Fluminense e na Universidade Estácio de Sá na mesma semana. O acirramento do debate político nas eleições brasileiras de 2018 também marcaria a obra do pesquisador que era surpreendido pelo intenso debate que tomava conta do país.

Entre 07 e 09 de novembro de 2018, Mario Losano palestrou sobre a crise da democracia parlamentar na Europa, na Faculdade de Direito da Universidade de São Paulo, sobre a vida e obra de Norberto Bobbio na Semana Norberto Bobbio, da Universidade Estadual Paulista, e sobre Drones e Direito, no Instituto Brasileiro de Ciências Criminais.

As vindas de Mario Losano ao Brasil entre 2012 e 2018 foram brevemente descritas acima. Mas as palavras aqui registradas são ínfimas para descrever a generosidade, a paciência e a humildade de Losano com os pesquisadores brasileiros. Losano cativou todos pelo conhecimento e pela humanidade que possui em si,de forma que o presente artigo apenas resume fatos acadêmicos, mas que não podem sintetizar a grandeza do homem e do pesquisador que Mario Losano é.

\section{PALAVRAS FINAIS}

Em 2019 Mario Losano lançou um importante livro sobre as eleições presidenciais brasileiras. O livro "La Lilbertà d'insegnamento in Brasile e l'elezione del presidente 
Bolsonaro"14 discute as tensões ocorridas no país em 2018 com a eleição do presidente Jair Bolsonaro e as diversas censuras que o Poder Judiciário tentou impor às universidades públicas do Brasil que se manifestavam contra um candidato que, em muitas vezes, lembrava o discurso fascista.

Em 15 de agosto de 2019, Mario Losano retorna ao Brasil para alegria de todos os pesquisadores em direito do país. Esperamos que seu brilhantismo e seu entusiasmo com a pesquisa ainda persistam por muitos anos.

O presente artigo serve para deixar na memória de brasileiros e italianos a intensa e produtiva relação de Mario Losano com o Brasil. Uma relação de amizade, mas, essencialmente, uma relação de pesquisadores, que tem o direito como foco de debate, problematizando constantemente o mundo atual.

Por outro lado, o artigo também serve para homenagear Mario Losano e agradecê-lo pela imensa dedicação e exemplo que é para pesquisadores, professores e estudantes no Brasil. Obrigado, Mario!

\section{REFERÊNCIAS BIBLIOGRÁFICAS}

Cecília Caballero LOIS, Gustavo Silveira SIQUEIRA, Da teoria da norma à teoria do ordenamento: o positivismo jurídico entre Kelsen e Bobbio, Belo Horizonte, Arraes Editores, 2016.

Gustavo S. SIQUEIRA, História do Direito pelos movimentos sociais: cidadania, experiências e antropofagia jurídica nas Estradas de Ferro (Brasil, 1906), Rio de Janeiro, Lumen Juris, 2014.

Gustavo Silveira SIQUEIRA, O parecer de Kelsen sobre a Constituinte brasileira de 1933-1934 / The Kelsen`s work about Brazilian Constituent 1933-1934, «Revista Direito e Práxis», 2015, [S.1.], v. 6, n. 2, p. 348-374.

\footnotetext{
${ }^{14}$ Mario LOSANO, La Libertà d'insegnamento in Brasile e l'elezione del presidente Bolsonaro, Milano, Mimeses, 2019.
} 
Gustavo Silveira SIQUEIRA, Pequeno ensaio sobre antropofagia jurídica: por uma sociologia histórica do direito brasileiro?, «Revista da Faculdade de Direito UFPR», 2016, v. 61, n. 1, p. 303-312.

Gustavo S. SIQUEIRA, Republic and Strike Action in the Beginning of the 20th Century: A Debate between the 1906 Strike and Legal History, in María Rosario POLOTTO, Thorsten KEISER, Thomas DUVE (eds.), Derecho privado y modernización: América Latina y Europa en la primera mitad del siglo XX, Global Perspectives on Legal History, Frankfurt am Main, Max Planck Institute for European Legal History, 2015, v. 1, p. 199-211, Open Access Publication, http://dx.doi.org/10.12946/gplh2.

Mario LOSANO, La Libertà d'insegnamento in Brasile e l'elezione del presidente Bolsonaro, Milano, Mimeses, 2019.

Mario LOSANO, O parecer de Hans Kelsen de 1933 sobre a Assembleia Nacional Constituinte do Brasil - Parecer em alemão, espanhol e italiano, «Revista Direito e Práxis», 2016, [S.1.], v. 7, n. 2, p. 624-648.

Mario G. LOSANO, O valor da justiça na obra de Kelsen, «Revista da Faculdade de Direito UFPR», 2014, v. 59, n. 2, p. 31-45.

Mario G. LOSANO, Os grandes sistemas jurídicos, São Paulo, Martins Fontes, 2007.

Mario G. LOSANO, Tra Uruguay e Italia: Couture e Calamadrei, due giuristi democratici nell'epoca delle dittature europee, in María Rosario POLOTTO, Thorsten KEISER, Thomas DUVE (eds.), Derecho privado y modernización: América Latina y Europa en la primera mitad del siglo XX, Global Perspectives on Legal History, Frankfurt am Main, Max Planck Institute for European Legal History, 2015, p. 275-312, Open Access Publication, http://dx.doi.org/10.12946/gplh2.

Mario LOSANO, Sociologia Jurídica e Histórica, história do direito e, no Brasil, "antropofagia jurídica", «Revista Direito e Praxis», 2015, v. 6, n. 3. Texto publicado em italiano na Revista da Faculdade de Direito da Universidade Federal do Paraná: Mario LOSANO, Sociologia giuridica e storica e, in Brasile, "Antropofagia Giuridica", «Revista da Faculdade de Direito UFPR», 2015, v. 60, n. 2, p. 11-40.

Submetido em: 03/07/2019

Aceito em: 19/07/2019 